OPEN ACCESS

Edited by:

Renato Grillo,

Federal University of $A B C$, Brazil

Reviewed by:

Halley Oliveira,

Universidade Estadual de Londrina,

Brazil

Juliana Lischka Sampaio Mayer, Universidade Estadual de Campinas,

Brazil

*Correspondence:

Alejandro Pérez de Luque

alejandro.perez.luque@

juntadeandalucia.es

Specialty section:

This article was submitted to Green and Environmental Chemistry, a section of the journa

Frontiers in Environmental Science

Received: 09 February 2017 Accepted: 24 March 2017

Published: 10 April 2017

Citation:

Pérez-de-Luque A (2017) Interaction of Nanomaterials with Plants: What Do

We Need for Real Applications in Agriculture? Front. Environ. Sci. 5:12

doi: 10.3389/fenvs.2017.00012

\section{Interaction of Nanomaterials with Plants: What Do We Need for Real Applications in Agriculture?}

\author{
Alejandro Pérez-de-Luque * \\ Área de Mejora y Biotecnología, IFAPA Centro Alameda del Obispo, Córdoba, Spain
}

The number of published researching works related with applications of nanomaterials in agriculture is increasing every year. Most of such works focus on the synthesis of nanodevices, their characteristics as nanocarriers for controlled release of active substances, and their interaction (either positive or negative) with plants or microorganisms under controlled conditions. Important knowledge has been gained about the uptake and distribution of nanomaterials in plants, although there are still gaps regarding internalization inside plant cells. Nanoparticle traits and plant species greatly affect the interaction, and nanodevices can enter and move through different pathways (apoplast vs. symplast), what influences their effectiveness and their final fate. Depending on the effect we are expecting for a nanocarrier, the application method might be critical. However, in order to get that research used in the field, some problems must be addressed. First, the cost for escalating the production of nanodevices must be affordable with the current production cost of agricultural goods. Second, we need to be sure that a technology is safe before spreading it into the environment. Third, consumers will distrust a technology unfamiliar for them in the same way that happened with transgenic crops. We need to broaden our horizons and start looking for real practical approaches, filling the main gaps that hamper our jump from laboratory research into field applications.

Keywords: nanoparticles, smart delivery systems, nanocarriers, nanoagriculture, crop production

\section{IT'S PLENTY OF ROOM OUT THERE}

It is possible that Richard Feynman was not aware of the catalytic events he was starting with his lecture "There's plenty of room at the bottom" back in 1959 (Feynman, 1960). More than fifty years later, nanotechnology is starting to affect our lives and will shape the nearby future of many disciplines such as material sciences, electronic, medicine or pharmacology. But what about agriculture? Will this tiny revolution help to solve the problems that agriculture is facing, such as increasing production and reducing negative environmental impacts within a climate change scenario (Baulcombe et al., 2009)? That is something we want to believe in, but science is about facts and we need to work hard in order to prove it.

Agriculture can benefit through the development of more efficient and less contaminant agrochemicals (nanoformulations), devices that help to detect biotic or abiotic stresses before they can affect production (nanosensors), or new techniques for genetic manipulation allowing higher efficiency during plant breeding programs (Pérez-de-Luque and Hermosín, 2013; Fraceto et al., 2016). Because the topic is really broad, in this article we will focus on applications for the synthesis 
of a new generation of agrochemicals, either for plant protection or fertilization, using nanocarriers for controlled release and smart delivery systems. The idea is quite simple: nanodevices can help to deliver the agrochemicals in the right place at the right time and to reduce the action of external agents leading to losses by degradation, leaching, run-off, volatilization, etc. The expected effect should be a reduction in the amount of active chemicals incorporated into the plants and soils leading to a reduced negative impact on the environment.

However, a lot of research and knowledge is needed to accomplish those goals. Not only for the development and synthesis of nanocarriers and nanomaterials, but also for studying the interactions of such nanodevices with the plants and the environment. Indeed, it is necessary to study how plants absorb and uptake nanoparticles, how they move inside the plant, and how they interact with the plant cell.

\section{Plant Absorption and Uptake of Nanoparticles}

The plant uptake of nanoparticles is affected by several factors related to the nature of the nanoparticle itself, but also with the plant physiology and the interaction of the nanomaterials with the environment (Figure 1).

It is clear that nanoparticle traits will greatly influence its behavior, and hence if the plant will be able to absorb it. Size seems to be one of the main restrictions for penetration into plant tissues, and there are some reports about the maximum dimensions that plants allow for nanoparticles to move and accumulate inside the cells, usually with $40-50 \mathrm{~nm}$ as a size exclusion limit (González-Melendi et al., 2008; Corredor et al., 2009; Sabo-Attwood et al., 2012; Taylor et al., 2014). Additionally, the type of nanoparticle and its chemical composition is another factor influencing the uptake (Ma et al., 2010; Rico et al., 2011), whereas morphology has also been demonstrated as determinant in some cases (Raliya et al., 2016). Functionalization and coating of the nanomaterial surface can greatly change and alter the properties for its absorption and accumulation by the plant (Judy et al., 2012).

Plant species can differ in their physiology, and such differences result in variations regarding uptake of nanoparticles, as reported for example by Cifuentes et al. (2010), Larue et al. (2012), and Zhu et al. (2012). These works showed how crops species belonging to different botanical families, and exposed to either magnetic carbon-coated, titanium dioxide or gold nanoparticles respectively, presented diverse absorption and accumulation patterns inside the plants. But the ways of application are also crucial in order to determine how effectively a plant will internalize the nanomaterials: roots are specialized in absorption of nutrients and water, whereas leaves are developed for gas exchange and present a cuticle which hampers penetration of substances (Schwab et al., 2015).

But nanoparticles interact with other components of the environment, and it can affect their properties and their traits for being assimilated by plants (Figure 1). For example, humic acids and other organic matter present in the soil can lead to an improved stability and hence a better bioavailability of nanomaterials, whereas salt ions might induce precipitation and trigger a contrary effect (Navarro et al., 2008). Even more, the presence of other organisms, such as bacteria and fungi, influences the plant uptake of nanoparticles, mainly if those microorganisms establish symbiosis with plants as in the case of mycorrhizal fungi (Feng et al., 2013; Wang et al., 2016).

\section{Movement of Nanoparticles inside Plants}

Once the nanoparticles penetrate into the plant, there are two ways for them to move through tissues: the apoplast and the symplast (Figure 1). Apoplastic transport takes place outside the plasma membrane through the extracellular spaces, cell walls of adjacent cells and xylem vessels (Sattelmacher, 2001), whereas symplastic transport involves movement of water and substances between the cytoplasm of adjacent cells through specialized structures called plasmodesmata (Roberts and Oparka, 2003) and sieve plates. The apoplastic pathway is important for radial movement within plant tissues, and allows nanomaterials to reach the root central cylinder and the vascular tissues, for further movement upwards the aerial part (González-Melendi et al., 2008; Larue et al., 2012; Zhao et al., 2012; Sun et al., 2014). Once inside the central cylinder, nanoparticles can move toward the aerial part though the xylem, following the transpiration stream (Cifuentes et al., 2010; Larue et al., 2012; Wang et al., 2012; Sun et al., 2014). Nevertheless, reaching the xylem through the root implies crossing a barrier to the apoplastic pathway, the Casparian strip, which must be done following a symplastic way (Robards and Robb, 1972) via endodermal cells. Indeed, some nanomaterials can be stopped and accumulated at the Casparian strip (Larue et al., 2012; Sun et al., 2014; Lv et al., 2015). Another important symplastic transport is possible too, using the sieve tube elements in the phloem, and allowing distribution toward non-photosynthetic tissues and organs (Wang et al., 2012; Raliya et al., 2016). In the case of foliar applications, nanomaterials must cross the barrier the cuticle presents, following the lipophilic or the hydrophilic pathway (Schönherr, 2002). The lipophilic one involves diffusion through cuticular waxes, whereas the hydrophilic pathway is accomplished through polar aqueous pores presented in the cuticle and/or stomata (Eichert and Goldbach, 2008; Eichert et al., 2008). Because the diameter of cuticular pores has been estimated around $2 \mathrm{~nm}$ (Eichert and Goldbach, 2008), the stomatal pathway appears as the most likely route for nanoparticle penetration, with a size exclusion limit above $10 \mathrm{~nm}$ (Eichert et al., 2008).

The way nanomaterials move inside plants is really important, because it can give indications about what parts of the plant they can reach, and where they might end and accumulate. For example, if a kind of nanoparticles are transported mainly through the xylem and not the phloem, they will likely move mainly from root to shoot and leaves, and not downwards, so they should be applied to the roots in order to get a good distribution in the plant. On the contrary, if the nanoparticles show a good translocation through the phloem, application should be done via foliar spraying. In addition, nanomaterials moving along the phloem will likely accumulate in plant organs acting as sink, such as fruits and grains, so that is another important consideration when trying to avoid further human or 


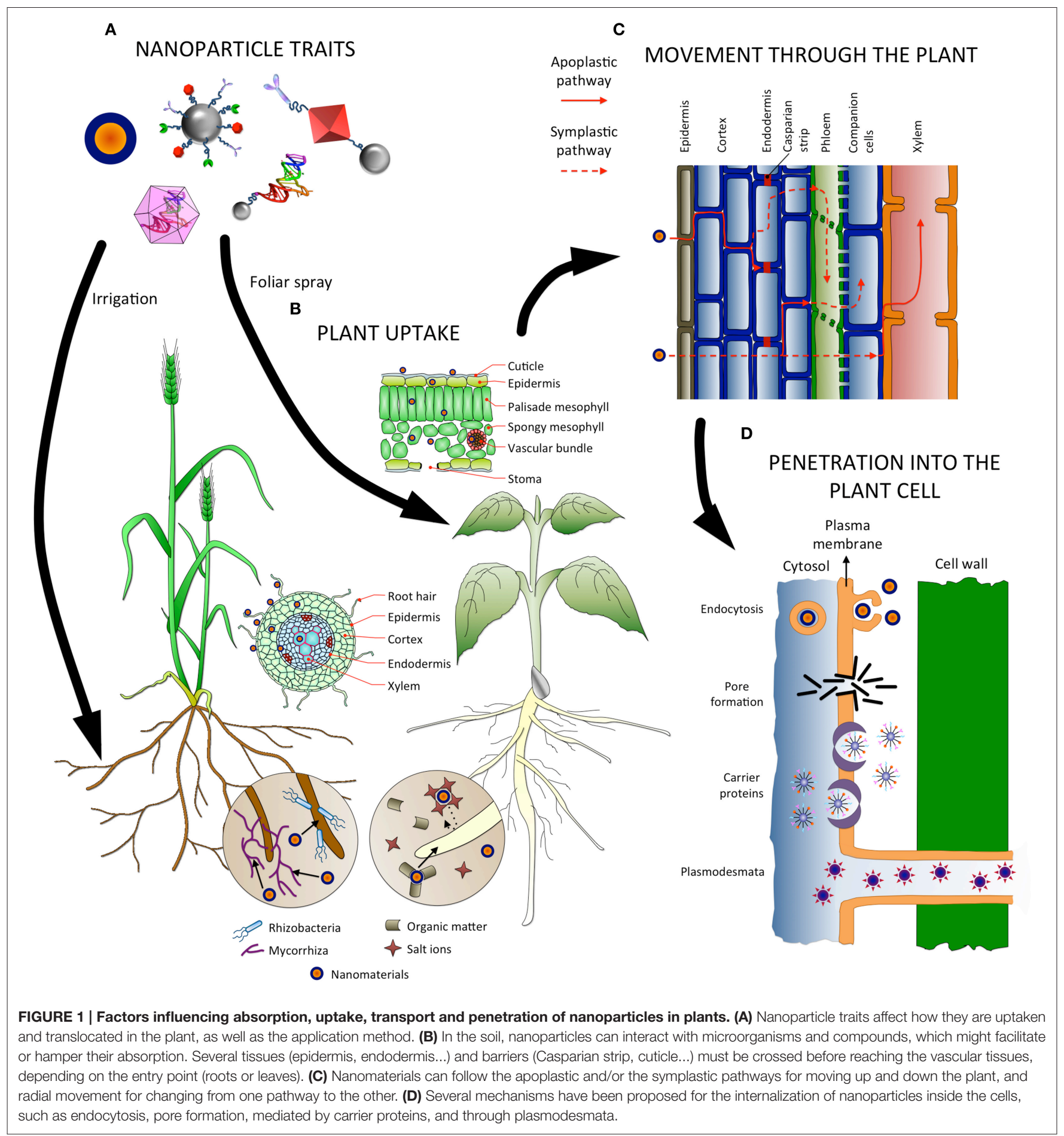

animal ingestion of nanomaterials. However, translocation is not necessarily restricted to a specific cell type, and lateral movement of nanomaterials between xylem and phloem is possible (Pate, 1975).

The characteristics and nature of the nanomaterials, in addition to the plant species, will greatly influence translocation and accumulation in plant tissues. For example, for the same kind of nanoparticle, differences in translocation and accumulation in different plant species have been observed (Cifuentes et al., 2010; Zhu et al., 2012), whereas slight differences in similar nanoparticles lead to different results within the same plant (Zhu et al., 2012). Cifuentes et al. (2010) reported higher accumulation of carbon-coated iron nanoparticles in the roots of pea compared with sunflower and wheat, and faster translocation to the aerial 
parts in pea and wheat compared with sunflower and tomato. On the other hand, Zhu et al. (2012) found that radish and ryegrass roots accumulated higher amounts of gold nanoparticles than rice and pumpkin, and that positively charged gold nanoparticles were taken up faster by the roots than negatively charged one, whereas these last ones were more efficiently translocated to the aerial parts. This phenomenon was explained by the negative charge present in the plant cell walls, favoring accumulation of positively charged nanoparticles in the tissues, and hampering its movement through the plant.

But, where do the nanomaterials go after being translocated to other parts? Typically, nanoparticles will accumulate in certain tissues and organs, in the same way it happens with animals (Varna et al., 2012). As commented above, plant organs acting as strong sinks for sap and nutrients are likely to accumulate nanomaterials traveling through the vascular system, mainly fruits (Servin et al., 2013), grains (Lin et al., 2009), flowers, and young leaves (Cifuentes et al., 2010; Koo et al., 2015). That is something to be used in our advantage when deciding the role of the nanomaterial we want to test. Do we need to deliver a plant hormone during flower development? Or an inhibitor for undesirable substances in the fruit? Perhaps a herbicide against a parasitic plant (Pérez-de-Luque and Rubiales, 2009)? It is also crucial to know the final fate of the nanomaterials if we do not want they to persist for human or animal consumption after the treatment. Some nanoparticles could be transformed or degraded by the plant after some time (Wang et al., 2012; Zhang et al., 2012; Lv et al., 2015), or simply being stored in tissues that will not be used after harvesting. In this last case, could they be recovered and recycled for further use (Liu et al., 2017)?

\section{Interaction of Nanomaterials with Plant Cells}

In order to enter the symplastic pathway, nanomaterials must be internalized by the plant cell and cross the plasma membrane (Figure 1). There are several ways for nanoparticles to achieve this, although such mechanisms are better studied in animal cells and less known in plants (Rico et al., 2011; Schwab et al., 2015):

- Endocytosis: The nanoparticles are incorporated into the cell by invagination of the plasma membrane, originating a vesicle that can travel to different compartments of the cell (Etxeberria et al., 2006).

- Pore formation: Some nanomaterials can disrupt the plasma membrane, inducing the formation of pores for crossing into the cell (Wong et al., 2016) and reaching directly the cytosol without being encapsulated in any organelle (Serag et al., 2011).

- Carrier proteins: Nanoparticles can bind to surrounding proteins, including cell membrane proteins that could act as carriers for internalization and uptake inside the cell (Nel et al., 2009). Specifically, aquaporins have been suggested as transporters for nanomaterials inside the cell (Rico et al., 2011), but their tiny pore size, ranging between 2.8 and $3.4 \AA$ (Wu and Beitz, 2007), makes them unlikely as channels for nanoparticle penetration (Schwab et al., 2015), unless such pore size could be modified and increased.
- Plasmodesmata: Another way for nanomaterials entering a cell is through plasmodesmata, specialized structures for transport between cells (Roberts and Oparka, 2003). Of course, it involves that the nanomaterials should be already in the symplast, but this mechanism is really important in plants for translocation through the phloem (Zhai et al., 2014).

- Ion channels: They have been proposed as probable pathways for nanoparticles entry into the cell (Rico et al., 2011; Schwab et al., 2015). However, the size of such channels is around $1 \mathrm{~nm}$, which makes very unlikely for nanoparticles to effectively cross them without important modifications.

How nanoparticles are internalized in the cells is another key question, because it will again influence the practical application of the nanomaterials. If we want to deliver chemicals inside specific cell organelles, then endocytosis appears as the most suitable way. On the contrary, for delivery in the cytosol, pore formation should be the most direct way for it. Additionally, we could be interested in nanomaterials that do not penetrate inside the plant cell but in other organisms, such as bacteria or fungi, in order to treat crop systemic diseases and infections (Rispail et al., 2014).

\section{BUT THE ROOM IS TOO BIG}

During the last years, the number of works dealing with the interaction between nanomaterials and plants has strongly increased. We are starting to get some views on how it works, but getting the whole picture is extremely complicated. Because Agricultural Science takes knowledge previously tested and performed in Medicine and Pharmacology, there are some problems when we try to implement such knowledge.

Firstly, Medicine focuses on one species, humans (or two or three if we consider animals for preliminary test and trials), whereas agriculture deals with more than 7,000 cultivated plant species (Khoshbakht and Hammer, 2008). This situation really complicates the research, because as stated previously, plant physiology affects the interaction with nanoparticles, so results observed in a crop are not necessarily valid for another one.

Secondly, the cost for escalating the production of nanomaterials can hamper their application in the fields. There are many good results with nanoparticles that appear promising as nanocarriers in plants. However, some studies are performed with a few plants/organisms in vitro or growth chamber because the cost (both, in time and money) for producing large amounts of the nanomaterial for greenhouse or field tests is not affordable. In the case of medical applications, a (relatively) high production cost can be accepted, but for agricultural production that is not possible and nanomaterials should be produced in great amounts and for a very low price. Promising works in this direction are those dealing with natural polymers such as chitosan (Grillo et al., 2014; Maruyama et al., 2016) and alginate (Silva et al., 2010), and lipids (Pérez-de-Luque et al., 2012; Campos et al., 2015a; de Oliveira et al., 2015). This kind of polymers are easily synthesized and produced from natural existing compounds like chitin from crustaceans' exoskeleton (for chitosan) and from brown algae (for alginate) 
(for a review, see Campos et al., 2015b), and they can be obtained in high amounts with a low cost.

Thirdly, this technology involves releasing nanomaterials into the field and inside the crops, so the first alarm bells: are these nanodevices safe for the environment and human/animal consumption? Despite nanotoxicological studies are being developed and carried out in different ways, even involving the food chain (Koo et al., 2015), the best way to avoid toxic effects is using materials that we already know are innocuous. Using certain metal/oxide nanoparticles or nanotubes for edible crop treatments does not seem a good idea. Perhaps under certain circumstances (for example, ornamental plants) would be possible to use some slightly hazardous nanomaterials in a controlled environment, but common sense and caution should be applied here. Again, compounds allowing synthesis of carriers in the nanoscale, innocuous for living organisms and with biodegrading traits are very good candidates. As pointed out previously, chitosan and alginate are ideal materials for this task, being already used in the food industry due to their lack of toxicity, biodegradability and edibility (Zohri et al., 2010; Azevedo et al., 2014).

Finally, consumers tend to distrust a technology unfamiliar for them, so it is necessary to explain them what nanotechnology is and what it involves. We do not want to repeat the story of the genetically modified organisms again, and learn from that (Kah, 2015). As researchers, we have a responsibility for communicating this knowledge, so outreach and popular science activities are tools we have at our disposal for that goal.

In conclusion, nanotechnology has a good potential for applications in agriculture, but there is still a long way down to reach the field. It is impossible to know all the details about how a nanodevice will work in a particular crop, but we need to start with real field and in planta tests, solving some of the problems stated above (mainly escalating the production and avoiding hazardous and toxic materials). If we stay behind the frontier of basic research only, the risk of agricultural nanotechnology

\section{REFERENCES}

Azevedo, M. A., Bourbon, A. I., Vicente, A. A., and Cerqueira, M. A. (2014). Alginate/chitosan nanoparticles for encapsulation and controlled release of vitamin B2. Int. J. Biol. Macromol. 71, 141-146. doi: 10.1016/j.ijbiomac.2014.05.036

Baulcombe, D., Crute, I., Davies, B., Dunwell, J., Gale, M., Jones, J., et al. (2009). Reaping the Benefits: Science and the Sustainable Intensification of Global Agriculture. London: The Royal Society.

Campos, E. V., de Oliveira, J. L., da Silva, C. M., Pascoli, M., Pasquoto, T., Lima, R., et al. (2015a). Polymeric and solid lipid nanoparticles for sustained release of carbendazim and tebuconazole in agricultural applications. Sci. Rep. 5:13809. doi: 10.1038/srep13809

Campos, E. V., de Oliveira, J. L., Fraceto, L. F., and Singh, B. (2015b). Polysaccharides as safer release systems for agrochemicals. Agron. Sustain. Dev. 35, 47-66. doi: 10.1007/s13593-014-0263-0

Cifuentes, Z., Custardoy, L., de la Fuente, J. M., Marquina, C., Ibarra, M. R., Rubiales, D., et al. (2010). Absorption and translocation to the aerial part of magnetic carbon-coated nanoparticles through the root of different crop plants. J. Nanobiotechnology 8:26. doi: 10.1186/1477$3155-8-26$ becoming hype increases, hindering any further attempts for applications and research. A first step in that direction should be testing nanocarriers already available on crops under controlled conditions, i.e., greenhouse and/or growth chamber. Lipidic, alginate or chitosan nanoparticles should be ready for mass scale production in order to get the necessary amounts for such experiments. Comparisons of treatments between the commercial products and the nanoformulated ones are a must, in order to check if the conventional dose of the active compounds can be effectively reduced. That would involve inoculation with common pathogens affecting the crops in the case of pesticide testing, and measurements of the effectiveness controlling diseases compared with conventional treatments. For fertilizers, development of the crop, physiological parameters and yield measurements are necessary. If the performance of the nanoformulated compounds is better than the conventional ones, then a next step further is needed: the field experiments. The field testing is critical and the last step before we can be sure a nanoformulation will work. All the experiments developed previously in laboratory, growth chamber and greenhouse are performed under controlled conditions, and despite they can show promising results, it does not grant complete success in the field. Tests under field conditions should be similar to those performed in greenhouse or growth chamber, but using the procedures and techniques needed for the crop we are testing. They should involve all the steps of the crop cycle, from sowing/planting to harvest, including conventional treatments for comparison, and others than should be commonly applied, in order to check in they will interfere with the nanoformulated products and vice versa. After that, if the results are positive, we can say the nanoformulation works and is ready.

\section{AUTHOR CONTRIBUTIONS}

The author confirms being the sole contributor of this work and approved it for publication.

Corredor, E., Testillano, P. S., Coronado, M. J., González-Melendi, P., FernándezPacheco, R., Marquina, C. I., et al. (2009). Nanoparticle penetration and transport in living pumpkin plants: in situ subcellular identification. BMC Plant Biol. 9:45. doi: 10.1186/1471-2229-9-45

de Oliveira, J. L., Campos, E. V., Gonçalves da Silva, C. M., Pasquoto, T., Lima, R., and Fraceto, L. F. (2015). Solid lipid nanoparticles co-loaded with simazine and atrazine: preparation, characterization, and evaluation of herbicidal activity. $J$. Agric. Food Chem. 63:422-432. doi: 10.1021/jf5059045

Eichert, T., and Goldbach, H. E. (2008). Equivalent pore radii of hydrophilic foliar uptake routes in stomatous and astomatous leaf surfacesfurther evidence for a stomatal pathway. Physiol. Plant. 132, 491-502. doi: 10.1111/j.1399-3054.2007.01023.x

Eichert, T., Kurtz, A., Steiner, U., and Goldbach, H. E. (2008). Size exclusion limits and lateral heterogeneity of the stomatal foliar uptake pathway for aqueous solutes and water-suspended nanoparticles. Physiol. Plant. 134, 151-160. doi: 10.1111/j.1399-3054.2008.01135.x

Etxeberria, E., Gonzalez, P., Baroja-Fernandez, E., and Romero, J. P. (2006). Fluid phase endocytic uptake of artificial nano-spheres and fluorescent quantum dots by sycamore cultured cells: evidence for the distribution of solutes to different intracellular compartments. Plant Signal. Behav. 1, 196-200. doi: $10.4161 /$ psb.1.4.3142 
Feng, Y., Cui, X., He, S., Dong, G., Chen, M., Wang, J., et al. (2013). The role of metal nanoparticles in influencing arbuscular mycorrhizal fungi effects on plant growth. Environ. Sci. Technol. 47, 9496-9504. doi: 10.1021/es402109n

Feynman, R. P. (1960). There's plenty of room at the bottom. Eng. Sci. 23, 22-36.

Fraceto, L. F., Grillo, R., de Medeiros, G. A., Scognamiglio, V., Rea, G., and Bartolucci, C. (2016). Nanotechnology in agriculture: which innovation potential does it have? Front. Environ. Sci. 4:20. doi: 10.3389/fenvs.2016.00020

González-Melendi, P., Fernández-Pacheco, R., Coronado, M. J., Corredor, E., Testillano, P. S., Risueño, M. C., et al. (2008). Nanoparticles as smart treatment-delivery systems in plants: assessment of different techniques of microscopy for their visualisation in plant tissues. Ann. Bot. 101, 187-195. doi: $10.1093 / \mathrm{aob} / \mathrm{mcm} 283$

Grillo, R., Pereira, A. E., Nishisaka, C. S., de Lima, R., Oehlke, K., Greiner, R., et al. (2014). Chitosan/tripolyphosphate nanoparticles loaded with paraquat herbicide: an environmentally safer alternative for weed control. J. Hazard. Mater. 278, 163-171. doi: 10.1016/j.jhazmat.2014.05.079

Judy, J. D., Unrine, J. M., Rao, W., Wirick, S., and Bertsch, P. M. (2012). Bioavailability of gold nanomaterials to plants: importance of particle size and surface coating. Environ. Sci. Technol. 46, 8467-8474. doi: 10.1021/es3019397

Kah, M. (2015). Nanopesticides and nanofertilizers: emerging contaminants or opportunities for risk mitigation? Front. Chem. 3:64. doi: 10.3389/ fchem.2015.00064

Khoshbakht, K., and Hammer, K. (2008). How many plant species are cultivated? Genet. Resour. Crop Evol. 55, 925-928. doi: 10.1007/s10722-008-9368-0

Koo, Y., Wang, J., Zhang, Q., Zhu, H., Chehab, E. W., Colvin, V. L., et al. (2015). Fluorescence reports intact quantum dot uptake into roots and translocation to leaves of Arabidopsis thaliana and subsequent ingestion by insect herbivores. Environ. Sci. Technol. 49, 626-632. doi: 10.1021/es5050562

Larue, C., Veronesi, G., Flank, A. M., Surble, S., Herlin-Boime, N., and Carrière, M. (2012). Comparative uptake and impact of $\mathrm{TiO}_{2}$ nanoparticles in wheat and rapeseed. J. Toxicol. Environ. Health A 75, 722-734. doi: 10.1080/15287394.2012.689800

Lin, S., Reppert, J., Hu, Q., Hudson, J. S., Reid, M. L., Ratnikova, T. A., et al. (2009). Uptake, translocation, and transmission of carbon nanomaterials in rice plants. Small 5, 1128-1132. doi: 10.1002/smll.200801556

Liu, H., Ren, M., Qu, J., Feng, Y., Song, X., Zhang, Q., et al. (2017). A cost-effective method for recycling carbon and metals in plants: synthesizing nanomaterials. Environ. Sci.: Nano 4, 461-469. doi: 10.1039/C6EN00287K

Lv, J., Zhang, S., Luo, L., Zhang, J., Yangc, K., and Christie, P. (2015). Accumulation, speciation and uptake pathway of $\mathrm{ZnO}$ nanoparticles in maize. Environ. Sci. Nano 2, 68-77. doi: 10.1039/c4en00064a

Ma, X., Geisler-Lee, J., Deng, Y., and Kolmakov, A. (2010). Interactions between engineered nanoparticles (ENPs) and plants: phytotoxicity, uptake and accumulation. Sci. Total Environ. 408, 3053-3061. doi: 10.1016/j.scitotenv.2010.03.031

Maruyama, C. R., Guilger, M., Pascoli, M., Bileshy-José, N., Abhilash, P. C., Fraceto, L. F., et al. (2016). Nanoparticles based on chitosan as carriers for the combined herbicides imazapic and imazapyr. Sci. Rep. 6:19768. doi: 10.1038/srep19768

Navarro, E., Baun, A., Behra, R., Hartmann, N. B., Filser, J., Miao, A. J., et al. (2008). Environmental behavior and ecotoxicity of engineered nanoparticles to algae, plants, and fungi. Ecotoxicology 17, 372-386. doi: 10.1007/s10646-008-0214-0

Nel, A. E., Mädler, L., Velegol, D., Xia, T., Hoek, E. M., Somasundaran, P., et al. (2009). Understanding biophysicochemical interactions at the nano-bio interface. Nat. Mater. 8, 543-557. doi: 10.1038/nmat2442

Pate, J. S. (1975). "Exchange of solutes between phloem and xylem and circulation in the whole plant," in Transport in Plants I, eds M. H. Zimmermann and J. A. Milburn (Berlin; Heidelberg: Springer), 451-473.

Pérez-de-Luque, A., Cifuentes, Z., Beckstead, J. A., Sillero, J. C., Avila, C., Rubio, J., et al. (2012). Effect of amphotericin B nanodisks on plant fungal diseases. Pest Manag. Sci. 68, 67-74. doi: 10.1002/ps.2222

Pérez-de-Luque, A., and Hermosín, C. (2013). "Nanotechnology and its use in agriculture," in Bio-Nanotechnology: A Revolution in Food, Biomedical and Health Sciences, eds D. Bagchi, M. Bagchi, H. Moriyama, and F. Shahidi (Oxford: Blackwell Publishing Ltd.), 383-398.

Pérez-de-Luque, A., and Rubiales, D. (2009). Nanotechnology for parasitic plant control. Pest Man. Sci. 65, 540-545. doi: 10.1002/ps.1732
Raliya, R., Franke, C., Chavalmane, S., Nair, R., Reed, N., and Biswas, P. (2016) Quantitative understanding of nanoparticle uptake in watermelon plants. Front. Plant Sci. 7:1288. doi: 10.3389/fpls.2016.01288

Rico, C. M., Majumdar, S., Duarte-Gardea, M., Peralta-Videa, J. R., and GardeaTorresdey, J. L. (2011). Interaction of nanoparticles with edible plants and their possible implications in the food chain. J. Agric. Food Chem. 59, 3485-3498. doi: $10.1021 /$ jf104517j

Rispail, N., De Matteis, L., Santos, R., Miguel, A. S., Custardoy, L., Testillano, P., et al. (2014). Quantum dots and superparamagnetic nanoparticles interaction with pathogenic fungi: internalization and toxicity profile. ACS Appl. Mater. Interfaces 6, 9100-9110. doi: 10.1021/am501029g

Robards, A. W., and Robb, M. E. (1972). Uptake and binding of uranyl ions by barley roots. Science 178, 980-982. doi: 10.1126/science.178.4064.980

Roberts, A. G., and Oparka, K. J. (2003). Plasmodesmata and the control of symplastic transport. Plant Cell Environ. 26, 103-124. doi: 10.1046/j.1365-3040.2003.00950.x

Sabo-Attwood, T., Unrine, J. M., Stone, J. W., Murphy, C. J., Ghoshroy, S., Blom, D., et al. (2012). Uptake, distribution and toxicity of gold nanoparticles in tobacco (Nicotiana xanthi) seedlings. Nanotoxicology 6, 353-360. doi: 10.3109/17435390.2011.579631

Sattelmacher, B. (2001). The apoplast and its significance for plant mineral nutrition. New Phytol. 149, 167-192. doi: 10.1046/j.1469-8137.2001.00034.x

Schönherr, J. (2002). A mechanistic analysis of penetration of glyphosate salts across astomatous cuticular membranes. Pest Manag. Sci. 58, 343-351. doi: $10.1002 / \mathrm{ps} .462$

Schwab, F., Zhai, G., Kern, M., Turner, A., Schnoor, J. L., and Wiesner, M. R. (2015). Barriers, pathways and processes for uptake, translocation and accumulation of nanomaterials in plants-Critical review. Nanotoxicology 10, 257-278. doi: 10.3109/17435390.2015.1048326

Serag, M. F., Kaji, N., Gaillard, C., Okamoto, Y., Terasaka, K., Jabasini, M., et al. (2011). Trafficking and subcellular localization of multiwalled carbon nanotubes in plant cells. ACS Nano 5, 493-499. doi: 10.1021/nn102344t

Servin, A. D., Morales, M. I., Castillo-Michel, H., Hernandez-Viezcas, J. A., Munoz, B., Zhao, L., et al. (2013). Synchrotron verification of $\mathrm{TiO}_{2}$ accumulation in cucumber fruit: a possible pathway of $\mathrm{TiO}_{2}$ nanoparticle transfer from soil into the food chain. Environ. Sci. Technol. 47, 11592-11598. doi: 10.1021/es403368j

Silva, M. S., Cocenza, D. S., de Melo, N. F. S., Grillo, R., Rosa, A. H., and Fraceto, L. F. (2010). Alginate nanoparticles as a controlled release system for clomazone herbicide. Quim. Nova 33, 1868-1873. doi: 10.1590/S0100-40422010000900009

Sun, D., Hussain, H. I., Yi, Z., Siegele, R., Cresswell, T., Kong, L., et al. (2014). Uptake and cellular distribution, in four plant species, of fluorescently labeled mesoporous silica nanoparticles. Plant Cell Rep. 33, 1389-1402. doi: 10.1007/s00299-014-1624-5

Taylor, A. F., Rylott, E. L., Anderson, C. W., and Bruce, N. C. (2014). Investigating the toxicity, uptake, nanoparticle formation and genetic response of plants to gold. PLoS ONE 9:e93793. doi: 10.1371/journal.pone.0093793

Varna, M., Ratajczak, P., Ferreira, I., Leboeuf, C., Bousquet, G., and Janin, A. (2012). In vivo distribution of inorganic nanoparticles in preclinical models. J. Biomater. Nanobiotechnol. 3, 269-279. doi: 10.4236/jbnb.2012.322033

Wang, F., Liu, X., Shi, Z., Tong, R., Adams, C. A., and Shi, X. (2016). Arbuscular mycorrhizae alleviate negative effects of zinc oxide nanoparticle and zinc accumulation in maize plants-A soil microcosm experiment. Chemosphere 147, 88-97. doi: 10.1016/j.chemosphere.2015.12.076

Wang, Z., Xie, X., Zhao, J., Liu, X., Feng, W., White, J. C., et al. (2012). Xylem- and phloem-based transport of $\mathrm{CuO}$ nanoparticles in maize (Zea mays L.). Environ. Sci. Technol. 46, 4434-4441. doi: 10.1021/es204212z

Wong, M. H., Misra, R. P., Giraldo, J. P., Kwak, S. Y., Son, Y., Landry, M. P., et al. (2016). Lipid exchange envelope penetration (LEEP) of nanoparticles for plant engineering: a universal localization mechanism. Nano Lett. 16, 1161-1172. doi: 10.1021/acs.nanolett.5b04467

$\mathrm{Wu}$, B., and Beitz, E. (2007). Aquaporins with selectivity for unconventional permeants. Cell Mol Life Sci. 64, 2413-2421. doi: 10.1007/s00018-007-7163-2

Zhai, G., Walters, K. S., Peate, D. W., Alvarez, P. J., and Schnoor, J. L. (2014). Transport of gold nanoparticles through plasmodesmata and precipitation of gold ions in woody poplar. Environ. Sci. Technol. Lett. 1, 146-151. doi: $10.1021 /$ ez400202b 
Zhang, P., Ma, Y., Zhang, Z., He, X., Zhang, J., Guo, Z., et al. (2012). Biotransformation of ceria nanoparticles in cucumber plants. ACS Nano 6, 9943-9950. doi: 10.1021/nn303543n

Zhao, L., Peralta-Videa, J. R., Ren, M., Varela-Ramirez, A., Li, C., HernandezViezcas, J. A., et al. (2012). Transport of $\mathrm{Zn}$ in a sandy loam soil treated with $\mathrm{ZnO}$ NPs and uptake by corn plants: electron microprobe and confocal microscopy studies. Chem. Eng. J. 184, 1-8. doi: 10.1016/j.cej.2012.01.041

Zhu, Z. J., Wang, H., Yan, B., Zheng, H., Jiang, Y., Miranda, O. R., et al. (2012). Effect of surface charge on the uptake and distribution of gold nanoparticles in four plant species. Environ. Sci. Technol. 46, 12391-12398. doi: 10.1021/es301977w

Zohri, M., Alavidjeh, M. S., Haririan, I., Ardestani, M. S., Ebrahimi, S. E., Sani, H. T., et al. (2010). A comparative study between the antibacteria effect of nisin and nisin-loaded chitosan/alginate nanoparticles on the growthl of Staphylococcus aureus in raw and pasteurized milk samples. Probiotics Antimicrob. Proteins. 2, 258-266. doi: 10.1007/s12602-010-9047-2

Conflict of Interest Statement: The author declares that the research was conducted in the absence of any commercial or financial relationships that could be construed as a potential conflict of interest.

Copyright (C) 2017 Pérez-de-Luque. This is an open-access article distributed under the terms of the Creative Commons Attribution License (CC BY). The use, distribution or reproduction in other forums is permitted, provided the original author(s) or licensor are credited and that the original publication in this journal is cited, in accordance with accepted academic practice. No use, distribution or reproduction is permitted which does not comply with these terms. 